\title{
Luminescence of a novel Eu(diketonato)-epoxiphenanthroline complex and covalent coupling to peptides via the epoxigroup $\dagger$
}

\author{
Marina M. Lezhnina, $\ddagger^{* a}$ Diana Hofmann, ${ }^{b}$ Beatrix Santiago-Schübel, ${ }^{b}$ \\ Peter Klauth $^{b c}$ and Ulrich H. Kynast ${ }^{a}$
}

Received (in Victoria, Australia) 16th June 2012, Accepted 13th August 2012
DOI: 10.1039/c2nj40505a

The application of rare earth complexes in several techniques and technologies requires their strong, i.e. preferably covalent, fixation to a substrate. The particularly useful luminescence properties of - readily available - rare earth $\beta$-diketonate complexes can widely be maintained on co-ligation with an epoxi-functionalised 1,10-phenanthroline. The linkage of epoxidised 1,10-phenanthroline to common peptides and proteins proceeds to free $-\mathrm{SH}$ and $-\mathrm{NH}_{2}$ groups, with a clear preference for $-\mathrm{SH}$. Subsequent luminescence activation with $\mathrm{Eu}(\mathrm{ttfa})_{3}$ yields strongly emissive species, in which the $\mathrm{Eu}(\mathrm{ttfa})_{3}$ coordinates to the $N$-bidentate phenanthroline protruding from the peptide. Luminescence, FTIR, ESI-MS, NMR and life time measurements provide the evidence for successful anchoring of the marker to the peptides. Additionally, the optical properties have been evaluated against analogous Eu complexes in polymer matrices and solution. The procedure described holds the promise of a facile method for the detection of free - $\mathrm{SH}$ groups in biological entities and their discrimination from oxidised -S-S- bridges.

\section{Introduction}

The outstanding luminescent properties of rare earth complexes such as aromatic carboxylates and diketonates were recognised several decades ago. Next to persisting fundamental interest, they have received renewed attention more recently in various emerging fields of applications, such as e.g. (molecular) organic light emitting diodes, ${ }^{1}$ sensors, ${ }^{2}$ or bioassays. ${ }^{3}$ Particular impact is owed to the event of the commercialization of the DELFIA system, ${ }^{4}$ in which the long life emission decay time of many of such complexes is exploited to discriminate the characteristic rare earth emissions against inherent matrix emissions of biological matter. Thus, protein emission signals for example, fading on the nanosecond time scale, can almost completely be ignored, if the rare earth emission is monitored with a time

${ }^{a}$ Münster University of Applied Sciences, Dept. of Chemical Engineering, Stegerwaldstr. 39, 48565 Steinfurt, Germany. E-mail: marina@fh-muenster.de; Fax: + 49 (0)2551-962187; Tel: + 49 (0)2551-962187

${ }^{b}$ Jülich Research Centre, Central Division of Analytical Chemistry (ZCH), Wilhelm-Johnen-Straße, 52428 Jülich, Germany.

E-mail: d.hofmann@fz-juelich.de;Tel: + 49 (0)2461612202

${ }^{c}$ Niederrhein University of Applied Sciences, iNano Institute,

Reinarzstraße 49, 47805 Krefeld, Germany.

E-mail: peter.klauth@me.com; Tel: +49(0)2151-8224680

$\dagger$ Electronic supplementary information (ESI) available: FTIR spectra of all compounds; ESI MS, ${ }^{1} \mathrm{H}$ and ${ }^{13} \mathrm{C}$ NMR spectra and signal assignments for $\mathrm{Na}_{2} \mathrm{GluSH}$-phen; absorption and luminescence spectra of Mel-phen and Trigly-phen. See DOI: 10.1039/c2nj40505a

$\ddagger$ Presently on leave from Mari Technical State University Yoshkar-Ola, Institute of Physics, Lenin-pl. 3, 424 000,Yoshkar-Ola, Russia. delay of up to several hundred microseconds. Additional factors synergistically contribute to the usability of the rare earths in these applications, among them the narrow emission lines and the large (apparent) Stoke shifts as well as the quantum yields, which can amount to near unity.

Bidentate $\beta$-diketonates constitute one class of thoroughly investigated ligands, which led to a well founded understanding of the underlying excitation, energy transfer and emission mechanisms, as summarised and shown in corresponding reviews. ${ }^{5}$ In brief, the efficient luminescence of the complexes is facilitated by allowed, thus strong singlet ${ }^{1} \mathrm{~S}_{0} \rightarrow{ }^{1} \mathrm{~S}^{*}$ absorptions, followed by spin-orbit coupling supported, intra-ligand energy transfer to a ligand triplet state ${ }^{3} \mathrm{~T}$, from which the energy is transferred to the attached rare earth ion and eventually emitted from the characteristic, well known rare earth excited states, e.g. ${ }^{5} \mathrm{D}_{0}$ in $\mathrm{Eu}^{3+}$ or ${ }^{5} \mathrm{D}_{4}$ in $\mathrm{Tb}^{3+}$. Early investigations of rare earth diketonates already revealed the advantageous effect of co-coordination, ${ }^{6}$ which essentially removes coordinated water from the luminescent center. If the co-ligands exhibit suitable absorptions, they may additionally contribute to the overall optical properties; popular examples are aromatic chelators such as 1,10-phenanthroline or 2,2'-bipyridine. The eight-coordinate molecular complexes thus typically obtained are soluble in non-polar solvents or may even be evaporated intact. As convenient as this might seem in some instances, for many conceivable applications, it may be necessary however, to link these complexes to a matrix, be it of inorganic, organic, polymeric or biological nature. Thus, we are searching for complexes with versatile, reactive functional groups, readily allowing a covalent affixment to abovementioned matrices. 


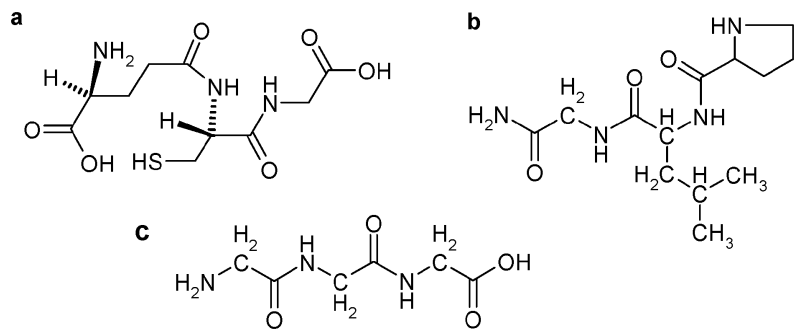

Fig. 1 Structure of analytes: (a) glutathione ("GluSH"), (b) melanostatine ("Mel"), (c) triglycine ("Trigly").

The present report is devoted to the use of the well known tris(2-thenyl-4,4,4-trifluorbutane-1,3-dionato) $\mathrm{Eu}$ (" $\mathrm{Eu}(\mathrm{ttfa})_{3}$ "), and 5,6-epoxy-5,6-dihydro-1,10-phenanthroline ("epoxiphen"), ${ }^{7}$ as a functional co-ligand. Its capability to bond and label the biologically relevant peptides glutathione ("GluSH"), triglycine ("Trigly"), and melanostatine ("Mel") is elucidated (see Fig. 1). Next to their presumed model character for the more cumbersome and complex reactions with proteins, GluSH, exhibiting free - $\mathrm{SH}$ groups, was chosen for its vital role as an antioxidant, and its indicator function for cellular toxicity, ${ }^{8}$ Trigly for the absence of $-\mathrm{SH}$ groups, and Mel, a melanin inhibitor, for its amide function and its exclusively secondary amine groups. ${ }^{9}$

\section{Results and discussion}

\section{Reactions of epoxiphen (5,6-epoxy-5,6-dihydro-1,10- phenanthroline) with peptides}

The expected reaction of epoxiphen with polar groups like amino and thiol, respectively, would generally proceed according to eqn (1a) or eqn (1b). ${ }^{10,11}$

The progress of the reaction can readily be followed by observing the disappearance of the asymmetric stretch of the epoxy C-O-C vibration in the infrared spectra (IR, $882 \mathrm{~cm}^{-1}$, see Fig. S1b, ESI $\dagger$ ). To confirm this assignment, a model reaction was carried out with glutathione and butylamine at $\mathrm{pH}=4$, the product of which was practically void of COC vibrations in the spectral range of interest (Fig. S1g, ESI $\dagger$ ).

The amine coupled reaction products la can in fact be identified for Trigly and Mel. However, a relatively high $\mathrm{pH}$ of 10 was required, while at a $\mathrm{pH}$ of 4 , no reaction could be observed at all. At intermediate $\mathrm{pH}$ values the reactions rates are drastically reduced, such that unreacted epoxiphen could still be detected even after a reaction period of 3 days.

As opposed to that, the thiole linkage appears to be preferred, as was demonstrated using GluSH, where the epoxiphen has completely vanished after 50 hours even at a $\mathrm{pH}$ as low as 4 .

The corresponding UV absorption spectra for the reactions of GluSH at pH 4 and 10 are reproduced in Fig. 2 along with the starting materials. At $\mathrm{pH}$ values of $>9$ the disappearance of the $\mathrm{H}-\mathrm{S}$ - valence mode $\left(2526 \mathrm{~cm}^{-1}\right)$ in the IR spectrum serves as an additional monitor for detection, furthermore, a slight shift of epoxiphen bands is observed (Fig. S1e, ESI $\dagger$ ), while products related to eqn (1a) (amine linkage) are not. Next to mentioned epoxy $\mathrm{C}-\mathrm{O}-\mathrm{C}$ vibrations, the solid epoxiphen ligand itself can be excited in the UV (250-400 nm) to exhibit a detectable emission in the blue to green spectral region, the

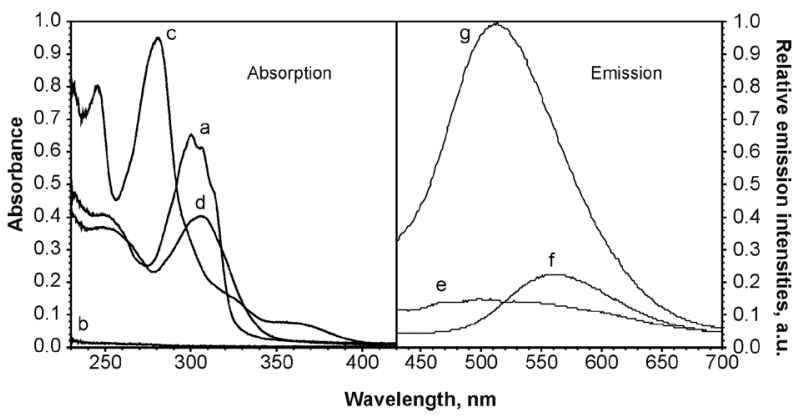

Fig. 2 Left: absorption spectra $\left(5 \times 10^{-5} \mathrm{~mol}^{-1}\right)$ of (a) epoxiphen, solids of (b) GluSH, (c) $\mathrm{H}_{2}$ GluS-phen (pH = 4), (d) $\mathrm{Na}_{2}$ GluS-phen ( $\mathrm{pH}=10$ ). Right: emission spectra of (e) epoxiphen, (f) $\mathrm{H}_{2}$ GluS-phen, (g) $\mathrm{Na}_{2}$ GluS-phen.

exact location of which appears to be depending on the ligand's substituents, i.e. $-\mathrm{NH}-\mathrm{R}$ or $-\mathrm{S}-\mathrm{R}$ (see Fig. S4 also, ESI $\dagger$ ). Qualitatively, the ligand emission spectra are blueshifted with increasing electron richness. Accordingly, the emission of the thiol coupled di-anion (the di-sodium salt, " $\mathrm{Na}_{2}$ GluS-phen") is also blueshifted by approximately $50 \mathrm{~nm}$, and, additionally, its emission intensity is enhanced considerably in the di-sodium salt over the free acid (Fig. 2).

Further evidence for the formation of the thiol-linked epoxiphen (eqn (1b), Scheme 1) can be derived from the corresponding MS and NMR spectra. In the ESI-MS in particular, significant fragmentation reactions are water releases and a characteristic cleavage of the fragment $\mathrm{H}_{2} \mathrm{NCH}\left(\mathrm{CH}_{2} \mathrm{~S}\right.$ phen) $\mathrm{CONHCH}_{2} \mathrm{COOH}(m / z=357 \mathrm{Da})$ (see Fig. S2, ESI $\dagger$ for further details). Because of the high ionization efficiency of the phen-group, several corresponding fragment ions appear, indicating the sulfur linkage. In contrast, bonds to oxygen or nitrogen would generate two other pairs of characteristic fragment ions each (215 and 197 or 214 and 196, respectively). Compared with this, MS spectra obtained for the amine based reaction of epoxiphen with $\mathrm{Mel}$ and Trigly indicate the presence of the amine linkage (Scheme 1, eqn (1a)), however, the Mel and Trigly materials were obviously strongly contaminated with unidentified by-products and starting materials, respectively, and were not pursued further (for completion, their absorption and emission spectra are depicted in Fig. S4, ESI $\dagger$ ). Finally, the NMR spectra agree with Fig. $1 \mathrm{~b}$ for the glutathione substitution also (see Experimental section). In addition the ${ }^{13} \mathrm{C}$ NMR data suggest the presence of two conformers in solution.

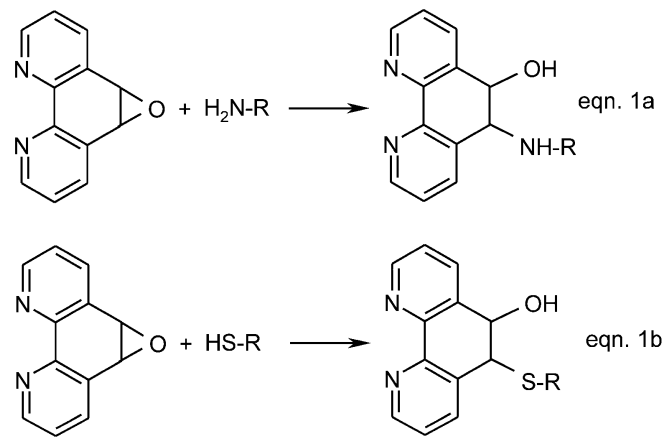

Scheme 1 Reaction pathways for coupling of epoxiphenanthroline. 


\section{The complex $\mathrm{Eu}(\mathrm{ttfa})_{3}$ epoxiphen}

While the preparation of epoxiphen, its conversion into aminophenanthroline and the successive complexation with $\mathrm{Eu}^{3+}$ to yield $\mathrm{Eu}(\mathrm{ttfa})_{3}$ aminophen ${ }^{13,14}$ has been reported, the complex $\mathrm{Eu}(\mathrm{ttfa})_{3}$ epoxiphen (Fig. 3) and its spectral features have to the best of our knowledge not been described before. This is somewhat surprising, because the epoxiphen co-ligand itself is easily accessible $^{7}$ (or even available commercially), grants a ready straightforward access to Eu(ttfa $)_{3}$ epoxiphen, which is in turn a very interesting complex due to the reactive epoxigroup. The co-ligand thus provides an elegant coupling substituent for numerous applications, in which covalent linkage to substrates is mandatory such as in sensors, markers, etc.

$\mathrm{Eu}(\mathrm{ttfa})_{3}$ epoxiphen proved to retain its spectral features and efficiency in comparison to the 'original' parent complex $\mathrm{Eu}(\mathrm{ttfa})_{3}$ phen (quantum yields $\Theta$ of $66 \%$ compared to $82 \%$ and corresponding lifetimes of $864 \mu$ s and $945 \mu$ s, respectively, we should mention here that other data reported for $\mathrm{Eu}(\mathrm{ttfa})_{3}$ phen amount to $69 \%$ and $976 \mu \mathrm{s}$, respectively, ${ }^{15}$ and $82 \%$, ${ }^{16}$ see Table 1).

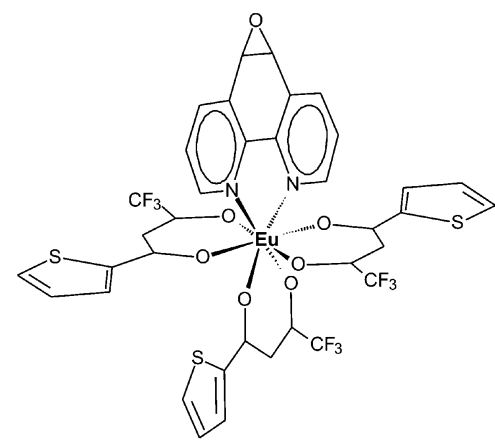

Fig. 3 Sketch of Eu(ttfa $)_{3}$ epoxiphen. Structural details of the parent $\mathrm{Eu}(\mathrm{ttfa})_{3}$ phen may be found in ref. 12 .

Table 1 Luminescence properties of Eu(ttfa $)_{3}$ epoxiphen and GluSHcoupled complexes: excitation and emission maxima $\left(\lambda_{\mathrm{exc}}, \lambda_{\mathrm{em}}\right)$, luminescence lifetimes $(\tau)$ and quantum yields $(\Theta)$ in comparison to other $\mathrm{Eu}(\mathrm{ttfa})_{3}$ containing species

\begin{tabular}{|c|c|c|c|c|}
\hline Sample & $\begin{array}{l}\lambda_{\mathrm{exc}} \\
(\mathrm{nm})\end{array}$ & $\begin{array}{l}\lambda_{\mathrm{em}} \\
(\mathrm{nm})\end{array}$ & $\tau(\mu \mathrm{s})$ & $\Theta(\%)$ \\
\hline $\mathrm{Eu}(\mathrm{ttfa})_{3}$ epoxiphen & 360 & 612 & 8642 & $66^{a}$ \\
\hline $\mathrm{Eu}(\mathrm{ttfa})_{3}$ phen & 380 & 612 & 94511 & $82^{a, b}, 69^{c}$ \\
\hline $\mathrm{Eu}(\mathrm{ttfa})_{3}\left(\mathrm{H}_{2} \mathrm{O}\right)_{2}$ & 375 & 610 & 1981 & $23^{c}$ \\
\hline $\mathrm{Eu}(\mathrm{ttfa})_{3}$ GluSH & 340 & 612 & $2661^{a}$ & - \\
\hline $\mathrm{Eu}(\mathrm{ttfa})_{3}$ GluS-phen & 360 & 612 & $\begin{array}{l}\tau_{1}: 16211(8 \%) \\
\tau_{2}: 494 \quad 8(92 \%)\end{array}$ & 20.6 \\
\hline $\mathrm{Eu}(\mathrm{ttfa})_{3}$ bu-aminophen ${ }^{d}$ & 360 & 612 & $5851^{a}$ & - \\
\hline $\mathrm{Eu}(\mathrm{ttfa})_{3}$ aminophenMR ${ }^{e}$ & 349 & 612 & 500 & $225^{f}$ \\
\hline Eu(ttfa) $)_{3}$ phen/PMMA & 360 & 612 & 5522 (spheres) & $35^{a}$ \\
\hline $\mathrm{Eu}(\mathrm{ttfa})_{3} / \mathrm{PMMA}$ & 350 & 615 & $\begin{array}{l}591(20 \%) \\
3623(80 \%)\end{array}$ & $0.6^{a}$ \\
\hline $\mathrm{Eu}(\mathrm{ttfa})_{3}$ phen/silicone & 365 & 612 & $526 \quad 1$ & 8 \\
\hline Eu(ttfa $)_{3}$ phen/PUR & 365 & 615 & 6011 & $36.7^{a}$ \\
\hline $\mathrm{Eu}(\mathrm{ttfa})_{3} / \mathrm{PUR}$ & 380 & 614 & 5581 & 17.6 \\
\hline \multicolumn{5}{|c|}{$\begin{array}{l}a^{a} \text { This work. }{ }^{b} \text { Ref. } 16 .{ }^{c} \text { Ref. } 15 .{ }^{d} \text { From reaction of epoxiphen with } \\
\text { butyl amine prior to complexation. }{ }^{e} \text { MR }=\text { Merrifield resin. }{ }^{f} \text { Ref. } 13 \\
\text { PUR = polyurethane (from hexamethylenediisocyanate and polyol), }{ }^{21} \\
\text { PMMA = polymethylmetacrylate. }\end{array}$} \\
\hline
\end{tabular}

\section{Functionalization of the epoxiphen coupled glutathione (GluS-phen) with $\mathrm{Eu}(\mathrm{ttfa})_{3}$}

The final functionalization of the epoxiphen-modified glutathione with $\mathrm{Eu}(\mathrm{ttfa})_{3}$ readily proceeds in a water-ethanol solution within a few hours (Scheme 2). Again, despite some band broadening, IR is a good tool for monitoring characteristic changes of the starting materials in the reaction.

IR absorptions of $\mathrm{Eu}(\mathrm{ttfa})_{3}$ and epoxiphen at 1580, 1560, $1433,1216,1013 \mathrm{~cm}^{-1}$ are shifted to higher frequencies on co-complexation according to Fig. S1 (ESI $\dagger$ ). The very same effects are also observed on co-complexation of GluS-phen to the europium diketonate. While on co-coordination of epoxiphen the characteristic $751 \mathrm{~cm}^{-1}$ absorption band (outof-plane bending modes of the hydrogen atoms) is red shifted and split into a doublet at approximately 744 and $721 \mathrm{~cm}^{-1}$, in GluSH-phen the corresponding $749 \mathrm{~cm}^{-1}$ band appears as a doublet at 746 and $720 \mathrm{~cm}^{-1}$ on coordination to $\mathrm{Eu}(\mathrm{ttfa})_{3}$. These findings are in complete agreement with the spectra reported for the co-coordination of 1,10-phenanthroline in similar complexes, e.g. $\mathrm{Eu}\left(\mathrm{O}_{2} \mathrm{C}-\mathrm{CH}=\mathrm{CH}-\mathrm{C}_{6} \mathrm{H}_{5}\right)_{3}$ phen $^{17}$ or $\mathrm{Eu}\left(\mathrm{NO}_{3}\right)_{3}$ (phen $)_{2} \cdot{ }^{18}$ Additionally, we observe redshifts of the phen absorptions at $800 \mathrm{~cm}^{-1}$ and $707 \mathrm{~cm}^{-1}$ to $786 \mathrm{~cm}^{-1}$ and $682 \mathrm{~cm}^{-1}$ on Eu-coordination and from $709 \mathrm{~cm}^{-1}$ to $682 \mathrm{~cm}^{-1}$, respectively, in the corresponding Eu(ttfa $)_{3}(\mathrm{GluS}-$ phen). The coordination of epoxiphen or GluS-phen also gives rise to a slight redshift from 1544 to $1539 \mathrm{~cm}^{-1}$ of the perturbed diketonate carbonyl groups of the ttfa ligand (Fig. S1, ESI $\dagger$ ).

Ultimately, spectroscopic evidence for the presence of the linkage between the $\mathrm{Eu}(\mathrm{ttfa})_{3}$ and the modified glutathione is provided by the spectral and lifetime analysis of the Eu emissions lines. The $\mathrm{Eu}^{3+}$ emission is known to be particularly sensitive to the chemical environment in that the presence of water or other entities exhibiting high vibrational frequencies in the first coordination sphere, inevitably lead to radiationless decays, i.e. reduced lifetimes of the excited states and reduced efficiencies.

Typically, 1,10-phenanthroline and other bidentate co-ligands to the diketonates provide very good screening and thus

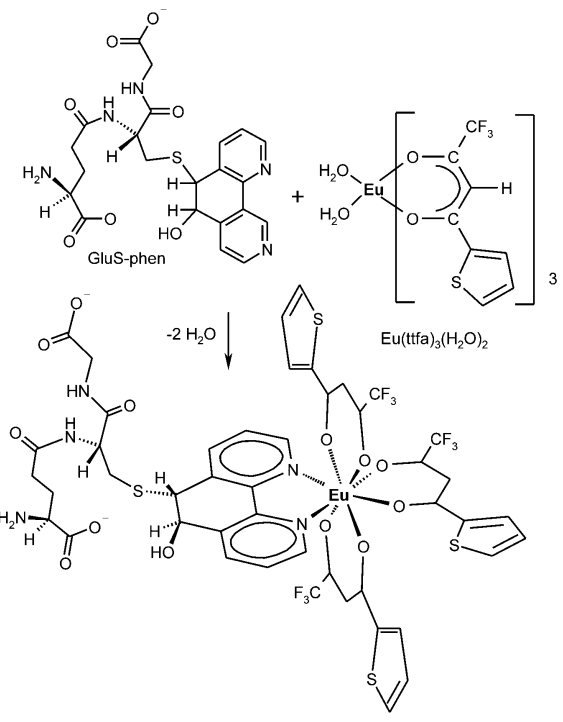

Scheme 2 Formation of Eu(ttfa $)_{3}$ GluSH-phen. 


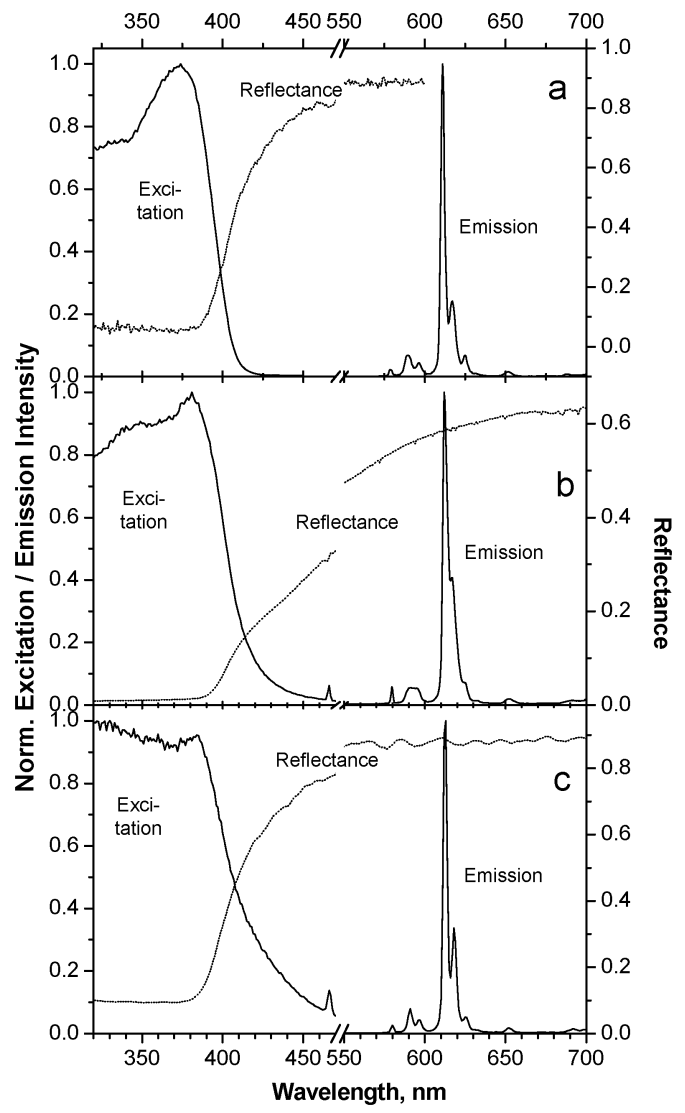

Fig. 4 Reflectance and normalised excitation and emission spectra of (a) Eu(ttfa $)_{3}$ phen $\left(\lambda_{\text {exc }}=380 \mathrm{~nm}\right)$, (b) Eu(ttfa) $)_{3}($ GluS-phen $)\left(\lambda_{\text {exc }}=\right.$ $360 \mathrm{~nm}$ ) and (c) Eu(ttfa) $)_{3}$ epoxiphen $\left(\lambda_{\text {exc }}=360 \mathrm{~nm}\right)$. Emission monitored at $612 \mathrm{~nm}$. The non-normalized emission intensity in $\mathrm{Eu}(\mathrm{ttfa})_{3}$ (GluS-phen) amounts to $c a .25 \%$ and $30 \%$ of $\mathrm{Eu}(\mathrm{ttfa})_{3}$ phen and $\mathrm{Eu}(\mathrm{ttfa})_{3}$ epoxiphen.

enable high efficiencies, often in excess of $80 \%$, which are accompanied by decay times up to the millisecond regime.

A comparison of the emission spectra of $\mathrm{Eu}(\mathrm{ttfa})_{3}$ phen, $\mathrm{Eu}(\mathrm{ttfa})_{3}$ epoxihen and $\mathrm{Eu}(\mathrm{ttfa})_{3}$ (GluS-phen) is enabled in Fig. 4. The emission pattern of Eu(ttfa) $)_{3}$ (GluS-phen) resembles that of $\mathrm{Eu}(\mathrm{ttfa})_{3}$ phen; the line broadening is analogous to that observed for attachment to the Merrifield resin. Thus the luminescence spectra support the assumption of structural analogy in the immediate $\mathrm{Eu}^{3+}$ coordination sphere. Further, Table 1 allows a quantitative comparison of the optical properties of the present $\mathrm{Eu}(\mathrm{ttfa})_{3}$ epoxiphen and $\mathrm{Eu}(\mathrm{ttfa})_{3}(\mathrm{GluS}-$ phen) with the parent compounds $\mathrm{Eu}(\mathrm{ttfa})_{3}$ and $\mathrm{Eu}(\mathrm{ttfa})_{3}$ phen as the pure compound and some matrix embedded materials. ${ }^{19,20}$ The increase of the radiative lifetimes of the $\mathrm{Eu}^{3+}$ ions on co-coordinating GluS-phen to $\mathrm{Eu}(\mathrm{ttfa})_{3}$ and the measured quantum yields are in good agreement with results found for mentioned phen-functionalised Merrifield resin (polystyrene) ${ }^{13}$ and generally in line with the decay depreciation brought about by secondary interactions of the complexes with "high frequency matrices" (-C-H vibrations of polymer matrices or other species, see Table 1). The GluS-phen ligand furthermore introduces a second lifetime component, albeit of weak amplitude (8\%) only, the assignment of which is not unambiguous at present. We speculate that a partial substitution of $\mathrm{ttfa}^{-}$by a GluS-phen carboxylate group due to the higher basicity of the $\mathrm{ttfa}^{-}$ligand may have taken place, a behaviour that we have previously observed at $\mathrm{pH}<7$ with other carboxylic acids. The formation of trace amounts of a Schiff-base from the GluS-phen aminofunctions and ttfa, analogous to $\beta$-diketonates of $\mathrm{Cu}^{2+}$ and $\mathrm{VO}^{2+}, 22,23$ should also not be ruled out.

\section{Summary and conclusions}

Well known diketonato complexes of $\mathrm{Eu}^{3+}$ can readily be co-coordinated with the bidentate co-ligand 5,6-epoxy-5,6dihydro-1,10-phenanthroline. The resulting luminescent complexes are thus enabled to undergo covalent coupling reactions with a multitude of conceivable reaction partners. However, in a series of reactions with amines and thiols we found a marked preference for coupling via -SH groups. It proved to be advantageous, to react the co-ligand with the epoxiphen prior to the eventual luminescence activation with the Eu diketonate complex Eu(tfa) $)_{3}$. Consequently, the reaction of epoxiphenanthroline with e.g. glutathione at moderate $\mathrm{pH}$ values exclusively leads to a sulfur linkage to the phenanthroline. The modified glutathione obtained can readily be functionalised optically with europium diketonates, such as $\mathrm{Eu}(\mathrm{ttfa})_{3}$, and thus be rendered luminescent. The scheme described holds the promise of becoming a sensitive optical sensor for glutathione, but possibly other biologically relevant molecules as well. As an example, the reduced form of BSA may be mentioned here, to which we were able to couple the complex as well. The epoxy complexes and the gluthathione derivatives were compared to known standard europium luminophores and found to be in a very promising efficiency regime optically. In future work, we will try to optimise the synthesis and investigate the detection limits for glutathione in particular. However, due to its capability of covalent binding, the complex is also of interest for the facile synthesis of inorganic-organic hybrid materials, i.e. for backbone anchored luminescent complexes within polymers, which will be a second focus in coming research.

\section{Experimental section}

\section{General experimental methods}

IR spectra were recorded on Perkin Elmer Spectrum One FTIR spectrometer as $\mathrm{KBr}$ disks in the range between $4000 \mathrm{~cm}^{-1}$ and $450 \mathrm{~cm}^{-1}$. A discussion of the relevant spectral features is conducted in the text. Given the multitude of absorption bands, a listing shall here be refrained from; instead, spectra are reproduced along with a comparison of relevant analogs in Fig. S1 (ESI $\dagger$ ).

Mass spectroscopic experiments were carried out on an Agilent 1100 series binary HPLC system (Agilent Technologies, Waldbronn, Germany) coupled with a 4000QTRAPTM linear ion trap mass spectrometer (Applied Biosystem/MDS SCIEX, Foster City, CA, USA) equipped with a TurboIon spray source. Separation was achieved on a ProntoSIL 120-C18-SH (Bischoff Chromatography, Leonberg, Germany) column $(150 \times 2 \mathrm{~mm}$ i.d., $3 \mu \mathrm{m}$ particle size) kept at $20{ }^{\circ} \mathrm{C}$ during analysis. Gradient elution was done with deionised water with $0.1 \%$ formic acid 
(solvent A) and acetonitrile with $0.1 \%$ formic acid (solvent B) at a constant flow rate of $300 \mu \mathrm{min}^{-1}$. The gradient profile was $1 \% \mathrm{~B}$ for $5 \mathrm{~min}$ isocratic, from 5 to $25 \mathrm{~min}$ a linear increase from $1 \%$ B to $99 \% \mathrm{~B}$, an isocratic step for $10 \mathrm{~min}$ and a return to $1 \% \mathrm{~B}$ at $26 \mathrm{~min}$ and $10 \mathrm{~min}$ isocratic for re-equilibration. The injection volume was $15 \mu \mathrm{l}$. The MS was operated in the positive Enhanced MS (EMS) mode ion scanning from 100-700 $\mathrm{nm}$. The parameters used for all methods were optimised performing a Flow Injection Analysis (FIA) with standards and led to the following settings for all analyses: curtain gas $\left(\mathrm{N}_{2}\right) 10$ arbitrary units $(\mathrm{au})$, temperature of the source $400{ }^{\circ} \mathrm{C}$, nebuliser gas $\left(\mathrm{N}_{2}\right) 50$ au and heater gas $\left(\mathrm{N}_{2}\right) 20 \mathrm{au}$. For compound identification MS/MS and MS/MS/MS experiments were performed in Enhanced Product Ion (EPI) Scan mode. Collision Energy (CE) was optimised individually for each precursor ion.

${ }^{1} \mathrm{H}$ and ${ }^{13} \mathrm{C}$ NMR spectra of $\mathrm{Na}_{2} \mathrm{GluS}$-phen were measured on an AVANCE I (Bruker) 400.13 MHz NMR spectrometer equipped with a $\mathrm{BBO}(\mathrm{F})$ sample head with a $z$-gradient. The sample was dissolved in $\mathrm{D}_{2} \mathrm{O}$ at a concentration of $0.187 \mathrm{~mol} \mathrm{l}^{-1}, 3$-(trimetylsilyl)propane sulfonic acid sodium salt (TSPSA) was used as an internal standard (chemical shift 0.015 ppm). ${ }^{13} \mathrm{C}$ spectra are $\mathrm{CH}$-decoupled.

UV-Vis absorption spectra were obtained using an Ocean Optics HR4000 fibre spectrometer with a $5 \mu \mathrm{m}$ slit and a $20 \mathrm{~W}$ deuterium/halogen light source. Emission and excitation spectra of the powderous products were measured at room temperature on an ARC spectrometer (monochromators of $300 \mathrm{~mm}$ focal length, a $450 \mathrm{~W}$ Xe lamp as a light source, photomultiplier tube P2) equipped with optical fibres. The quantum yields were obtained by measuring relative to a Lumogen Red F300 doped (50 ppm) PMMA powder standard, for which a quantum yield of $42 \%$ was assumed.

Luminescence decay times were measured using an Edinburgh Instruments FL 920 lifetime spectrometer (single photon counting) equipped with an Edinburgh Instruments $\mu$ F900 flash lamp and a Hamamatsu extended red sensitivity photomultiplier tube.

\section{Synthesis}

5,6-Epoxy-5,6-dihydro-1,10-phenanthroline (epoxiphen). Epoxiphen was synthesised according to Shen and Sullivan ${ }^{7}$ with the exception that the formation of epoxiphen was monitored via IR spectroscopy. The spectra were identical to a commercial product purchased from Aldrich.

Coupling of GluSH with (epoxiphen). $200 \mathrm{mg}$ GluSH (0.651 mmol, Aldrich) were dissolved in $10 \mathrm{ml}$ dest. water and mixed with $120 \mathrm{mg}$ 5,6-epoxy-5,6-dihydro-1,10-phenanthroline $(0.612 \mathrm{mmol})$, dissolved in $2 \mathrm{ml}$ methanol. The mixture was stirred at room temperature for at least $20 \mathrm{~h}$. The solvent was evaporated under vacuum $\left(10^{-3} \mathrm{mbar}\right)$ at room temperature. The yellow powderous product was washed several times with toluene. The toluene contained no residue after evaporation, if the reaction time exceeded $40 \mathrm{~h}$.

In ESI-MS, the signal of highest mass at 405 Da corresponds to the quasi molecular ion $[\mathrm{M}+\mathrm{H}]^{+}$of composition $\mathrm{C}_{22} \mathrm{H}_{26} \mathrm{~N}_{5} \mathrm{O}_{7} \mathrm{~S}^{+}$. The complete fragmentation scheme is given in Scheme S2 (ESI $\dagger$ ). For a discussion of relevant IR vibrations see text (further spectral information in Fig. S1, ESI $\dagger$ ).
Na 2 GluS-Phen. $200 \mathrm{mg}$ GluSH $(0.651 \mathrm{mmol})$ were dissolved in $10 \mathrm{ml}$ dest. water, the solution was adjusted with $2 \mathrm{M} \mathrm{NaOH}$ solution to a $\mathrm{pH}$ of 9 , and mixed with $127.4 \mathrm{mg} 1,10$-phenanthroline-5,6-epoxide $(0.65 \mathrm{mmol})$ dissolved in $2 \mathrm{ml}$ methanol. The mixture was stirred at room temperature for 20 to $45 \mathrm{~h}$, after which the solvents were evaporated under vacuum $\left(10^{-3}\right.$ mbar) at room temperature. The slightly yellowish powder was washed several times with toluene (at $45 \mathrm{~h}$ reaction time no residue was observed after evaporation of toluene). For the reaction at $\mathrm{pH} \approx 9$ of GluSH with epoxiphen, the highest signal in MS appears at $m / z=504$, corresponding to [GluSphen $+\mathrm{H}]^{+}\left(\mathrm{C}_{10} \mathrm{H}_{16} \mathrm{~N}_{3} \mathrm{O}_{6} \mathrm{~S}-\mathrm{HOC}_{12} \mathrm{H}_{9} \mathrm{~N}_{2}\right)$ (see text, Fig. $\mathrm{S} 1$ and Scheme $\mathrm{S} 1, \mathrm{ESI} \dagger)$. In NMR all signals can be assigned to the product indicated by eqn (1b), albeit in ${ }^{13} \mathrm{C}$, the appearance of doublets (some only under very strong magnification) suggests the presence of two fairly stable conformers in the solution:

${ }^{1} \mathrm{H}$ NMR $\delta_{\mathrm{H}} 1.88-1.87(\mathrm{~d}, 2 \mathrm{H}) ; 2.37(\mathrm{~s}, 2 \mathrm{H}) ; 2.805-2.92(\mathrm{~m}$, $1 \mathrm{H}) ; 3.1-3.32(\mathrm{~m}, 1 \mathrm{H}) ; 3.28(\mathrm{~s}, 1 \mathrm{H}) ; 3.80(\mathrm{~d}, 2 \mathrm{H}) ; 4.56(\mathrm{~s}, 1 \mathrm{H})$; $4.60(\mathrm{~d}, 1 \mathrm{H}) ; 5.18(\mathrm{~d}, 1 \mathrm{H}) ; 7.5-7.6(\mathrm{~m}, 2 \mathrm{H}) ; 8.00(\mathrm{dd}, 2 \mathrm{H}) ; 8.70$ $(\mathrm{d}, 1 \mathrm{H}) ; 8.75(\mathrm{~d}, 1 \mathrm{H}) .{ }^{13} \mathrm{C}$ NMR $\delta_{\mathrm{H}} 33.24(\mathrm{~s}) ; 34.91(\mathrm{~s}) ; 35.20$, 35.30 (d); 46.06 (s); 49.37, 49.88 (d); 55.13, 55.71 (d); 58.0 (s); 72.07, 72.35 (d); 127.95, 128.0 (d); 128.20 (s); 134.15, 134.27 (d); 134.41 (s); 141.55, 141.65 (d); 151.22, 151.23 (d); 151.45, 141.48 (d); 152.18, 152.27 (d); 153.1 (s); 174.11, 174.15 (d); $178.77,178.8$ (d); 178.9 (s); $184.22,184.26$ (d). The signals for GluSH strongly depend on $\mathrm{pH}$. The assignment summarised in Table S1 (ESI $\dagger$ ) follows previous assignments on GluSH. ${ }^{24,25}$

$\mathbf{E u}(\mathbf{t t f a})_{3}$ (epoxiphen). Eu(ttfa $)_{3}\left(\mathrm{H}_{2} \mathrm{O}\right)_{2}$ was prepared according to Charles and Ohlmann. ${ }^{26}$ The epoxiphen-cocomplex was subsequently obtained by dissolution of $0.851 \mathrm{~g} \mathrm{Eu(ttfa})_{3^{-}}$ $\left(\mathrm{H}_{2} \mathrm{O}\right)_{2}(1 \mathrm{mmol})$ in $15-20 \mathrm{ml}$ ethanol. $0.196 \mathrm{~g}$ epoxiphen were dissolved in $10 \mathrm{ml}$ ethanol and added to the previous solution and the mixture left overnight at room temperature for the complex crystallization. The powder was filtered off, washed with $n$-hexane and dried under vacuum at room temperature. Analytical data for $\mathrm{C}_{36} \mathrm{H}_{30} \mathrm{~N}_{2} \mathrm{O}_{3} \mathrm{~S}_{3} \mathrm{~F}_{9} \mathrm{Eu}$ : $\mathrm{Eu}$ $15.02 \%$, found $15.06 \%$; C $42.74 \%$, found $43.10 \%$; S $9.51 \%$, found $9.25 \%$.

Eu(ttfa) $)_{\mathbf{3}}\left(\mathbf{N a}_{\mathbf{2}}\right.$ GluS-phen). $200 \mathrm{mg} \mathrm{Na}{ }_{2}$ GluS-phen (0.364 mmol) were dissolved in $2 \mathrm{ml}$ dest. water and $7 \mathrm{ml}$ ethanol. $310 \mathrm{mg}$ $\mathrm{Eu}(\mathrm{ttfa})_{3}$ were dissolved in $1 \mathrm{ml}$ ethanol and added to the conjugated tripeptide solution. The precipitate formed was heated for $9 \mathrm{~h}$ at $50{ }^{\circ} \mathrm{C}$ with an additional $7 \mathrm{ml}$ of ethanol. After cooling the precipitate was centrifuged and washed several times with ethanol to remove non-reacted $\mathrm{Eu}(\mathrm{ttfa})_{3}$. Yield 30\%. Analytical data for $\mathrm{Na}_{2} \mathrm{C}_{46} \mathrm{H}_{35} \mathrm{~N}_{5} \mathrm{O}_{13} \mathrm{~S}_{4} \mathrm{~F}_{9} \mathrm{Eu}$ : Eu $11.15 \%$ (found $11.10 \%$ ), C $40.54 \%$ (found $40.72 \%$ ), S 9.38\% (found $9.40 \%$ ).

\section{Acknowledgements}

M.L., P.K. and U.K. gratefully acknowledge financial support from the German Ministry of Education and Technology (BMBF, FKZ FKZ 1724A05, 1724B05). The authors express their gratitude to The University of Muenster, Institute of Organic Chemistry, for recording NMR spectra. 


\section{Notes and references}

1 J. Kido and Y. Okamoto, Chem. Rev., 2002, 102, 2357.

2 D. Parker, Coord. Chem. Rev., 2000, 205, 109; J. P. Leonard and T. Gunnlaugsson, J. Fluoresc., 2005, 4, 585.

3 R. B. Martin and F. S. Richardson, Q. Rev. Biophys., 1979, 12, 181; J.-C. G. Bünzli, Chem. Rev., 2010, 5, 2729; P. R. Selvin, Annu. Rev. Biophys. Biomol. Struct., 2002, 31, 275.

4 I. Hemmilä, Scand. J. Clin. Lab. Invest., 1988, 48, 389; I. Hemmilä, in Time-Resolved Fluorometric: Immunoassays Instrumentation, Applications, Unresolved Issues and Future Trends, in Standardization and Quality Assurance in Fluorescence measurements II, ed. U. Resch-Genger, Springer, Berlin Heidelberg, 2008, pp. 429-447.

5 G. F. de Sa, O. L. Malta, C. de Mello Donega, A. M. Simas, R. L. Longo, P. A. Santa-Cruz and E. F. da Silva Jr, Coord. Chem. Rev., 2000, 196, 165; K. Binnemans, in Handbook on the Physics and Chemistry of Rare Earths, ed. K. A. Gschneidner Jr, J.-C. G. Bünzli and V. K. Pecharsky, Elsevier BV, 2005, vol. 35, ch. 225, pp. 107-272; J.-C. Buenzli, Chem. Rev., 2010, 110, 2729; H. F. Brito, O. M. L. Malta, M. C. F. C. Felinto and E. E. de Sousa Teotonio, in The Chemistry of Metal Enolates, ed. J. Zabicky, John Wiley \& Sons, 2009, ch. 3, (Luminescence Phenomena involving metal enolates), pp. 131-184.

6 V. L. Ermolaev, V. G. Aleshin and E. A. Saenko, Dokl. Akad. Nauk SSSR, 1965, 165, 1048; C. de Mello Donega, S. Alves and G. F. de Sa, J. Alloys Compd., 1997, 250, 422; Y. Hasegawa, M. Miratsu and G. R. Choppin, Anal. Chim. Acta, 2001, 428, 149; S. V. Eliseeva, D. N. Pleshkov, K. A. Lyssenko, L. S. Lepnev, J.-C. Bünzli and N. P. Kuzmina, Inorg. Chem., 2010, 49, 9300; S. V. Eliseeva, D. N. Pleshkov, K. A. Lyssenko, L. S. Lepnev, J.-C. Bümzli and N. P. Kuzmina, Inorg. Chem., 2011, 50, 5137.

7 Y. Shen and B. P. Sullivan, Inorg. Chem., 1995, 34, 6235.

8 Y. Ishiara, M. Oka, M. Tsunakawa, K. Tomita, M. Hatori, H. Yamamoto, H. Kamei, T. Miyaki, M. Konishi and T. Oki, J. Antibiot., 1991, 44, 25.

9 T. M. Bray and C. G. Taylor, Biochem. Pharmacol., 1994, 47, 2113.

10 H. Fraenkel-Conrat, J. Biol. Chem., 1944, 154, 227.
11 M. C. I. A. Dotsenko, N. M. Samoshina and V. V. Samoshin, Tetrahedron, 2011, 67, 7470 .

12 M. L. Hu, Z. Y. Huang, Y. Q. Cheng, S. Wang, J. J. Lin, Y. Hu, D. J. Xu and Y. Z. Xu, Chin. J. Chem., 1999, 17, 637.

13 P. Lenaerts, K. Driesen, R. Van Deun and K. Binnemans, Chem. Mater., 2005, 17, 2148; K. Binnemans, P. Lenaerts, K. Driesen and C. Görller-Warland, J. Mater. Chem., 2004, 14, 191.

14 J.-P. Duan, P.-P. Sun and C.-H. Cheng, J. Mater. Online, DOI: 10.2240/azojomo0151 (Azojomo; http://www.azom.com/details.as p?ArticleID = 3073), posted Oct., 2005, last accessed June, 8th, 2012).

15 F. R. G. e Silva, J. F. S. Menezes, G. B. Rocha, S. Alves, H. F. Brito, R. L. Longo and O. L. Malta, J. Alloys Compd., 2000, 303, 364.

16 G. Bourhill, L. O. Palsson, I. D. W. Samuel, I. C. Sage, I. D. H. Oswald and J. P. Duignan, Chem. Phys. Lett., 2001, 336, 234-241.

17 I. V. Kalinovskaya, V. E. Karasev, A. N. Zadorozhnaya and L. I. Lifar, Russ. J. Coord. Chem., 2001, 27, 516.

18 V. Tsaryuk, V. Zolin, L. Puntus, V. Savchenko, J. Legendziewicz, J. Sokolnicki and R. Szostak, J. Alloys Compd., 2000, 300, 184.

19 EP 1316570 Al, 2002.

20 P. Klauth, A. Joschko, P. Ustohal, J. Büddefeld, E. Klumpp, H. Vereecken, M. Lezhnina and U. Kynast, Colloids Surf., A, 2008, 325, 173.

21 M. Hilder, P. C. Junk, M. M. Lezhnina, M. Warzala and U. H. Kynast, J. Alloys Compd., 2008, 451, 530.

22 C. Pereira, S. Patricio, A. R. Silva, A. P. Carvalho, J. Pires and C. Freire, J. Colloid Interface Sci., 2007, 316, 570.

23 C. Pereira, A. R. Silva, A. L. Malaghaes, A. P. Carvalho, J. Pires and C. Freire, J. Mol. Catal. A: Chem., 2008, 283, 5.

24 G. Jung, E. Breitmaier and W. Voelter, Eur. J. Biochem., 1972, 24, 438.

25 A. Corazza, I. Harvey and P. Sadler, Eur. J. Biochem., 1996, 236, 697.

26 R. G. Charles and R. C. Ohlmann, J. Inorg. Nucl. Chem., 1965, 27, 255. 